\title{
Bioensaio com Allium cepa revela genotoxicidade de herbicida com flumioxazina
}

\author{
Allium cepa bioassay reveals genotoxicity of flumioxazin herbicide \\ Lais Gonçalves Parvan' (D), Thaís Gonçalves Leite ${ }^{(1 D}$, Thaynara Barbosa Freitas' (D), Polyana Aparecida Almeida \\ Pedrosa' (D), Juliana Sena Calixto2 (iD), Luciana de Andrade Agostinho 1,3,4 (D) \\ ${ }^{1}$ Centro Universitário UNIFAMINAS, Muriaé, Minas Gerais, Brasil \\ 2 Instituto Federal de Educação, Ciência e Tecnologia do Sudeste de Minas Gerais, Muriaé, Minas Gerais, Brasil \\ ${ }^{3}$ Fundação Cristiano Varella, Hospital do Câncer de Muriaé, Muriaé, Minas Gerais, Brasil \\ ${ }^{4}$ Universidade Federal do Estado do Rio de Janeiro, Programa de Pós-Graduação em Neurologia, Rio de Janeiro, Rio de Janeiro, Brasil
}

\begin{abstract}
RESUMO
OBJETIVO: Analisar o potencial genotóxico de um herbicida com flumioxazina pelo bioensaio Allium cepa. MATERIAIS E MÉTODOS: O herbicida foi testado em duas concentrações: 0,5 g/L (concentração indicada para o uso) e 1,0 g/L (dobro da concentração recomendada). Foram utilizados água destilada como controle negativo e, como controle positivo de citotoxicidade, benzoato de sódio 1\%. RESULTADOS: Os resultados obtidos evidenciaram efeitos de toxicidade em ambas as concentrações do herbicida. Efeitos de citotoxicidade foram observados no herbicida com flumioxazina na concentração de $0,5 \mathrm{~g} / \mathrm{L}$, que apresentou padrão microscópico igual ao do controle positivo. Os efeitos de genotoxicidade foram observados em ambas as concentrações $(0,5 \mathrm{~g} / \mathrm{L}$ e 1,0 g/L) que resultaram em aberrações cromossômicas nas células, mostrando que o herbicida interfere diretamente no ciclo celular das células vegetais da cebola. CONCLUSÃO: O herbicida com flumioxazina apresentou toxicidade e genotoxicidade nas concentrações analisadas e efeitos de citotoxicidade somente na concentração recomendada para o uso.
\end{abstract}

Palavras-chave: Genotoxicidade; Allium cepa; Herbicidas; Índice Mitótico.

\begin{abstract}
OBJECTIVE: To analyze the genotoxic potential of an herbicide with flumioxazin using the Allium cepa bioassay. MATERIALS AND METHODS: The herbicide was tested in two concentrations: $0.5 \mathrm{~g} / \mathrm{L}$ (as indicated for use) and $1.0 \mathrm{~g} / \mathrm{L}$ (twice the recommended concentration). Distilled water was used as a negative control and $1 \%$ sodium benzoate as a positive cytotoxicity control. RESULTS: Toxicity effects were evidenced in both herbicide concentrations. Cytotoxicity effects were observed in the herbicide with flumioxazin at a concentration of $0.5 \mathrm{~g} / \mathrm{L}$, which showed a microscopic pattern equal to that of the positive control. The effects of genotoxicity were observed at both concentrations $(0.5 \mathrm{~g} / \mathrm{L}$ and $1.0 \mathrm{~g} / \mathrm{L})$ which resulted in chromosomal aberrations in cells, showing that the herbicide directly interferes with the cell cycle of vegetal onion cells. CONCLUSION: The herbicide with flumioxazin showed toxicity and genotoxicity in the analyzed concentrations and effects of cytotoxicity only in the concentration recommended for use.
\end{abstract}

Keywords: Genotoxicity; Allium cepa; Herbicides; Mitotic Index.

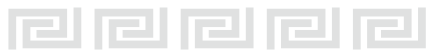

\section{INTRODUÇÃO}

A industrialização e o crescimento desenfreado das atividades associadas à agricultura e ao comércio têm gerado consequências prejudiciais à saúde humana e ambiental. Diversos estudos evidenciaram a presença de resíduos de substâncias químicas nos alimentos, nas águas, no solo e em diversos organismos, devido ao uso indiscriminado de agrotóxicos, que possuem propriedades bioacumulativas ${ }^{1,2,3,4}$.
Dados do Sistema Nacional de Informações Tóxico-Farmacológicas (Sinitox) mostraram quase 30.000 casos de pessoas intoxicadas por agrotóxicos, no período de 2007 a 2014, o equivalente à média de oito intoxicações diárias. A mortalidade foi de 0,26\% $(78 / 30.000 \text { casos })^{5,6}$. Com a atualização dos dados, no ano de 2017, foi verificado um aumento significativo tanto no número total de casos (76.115) como na média de intoxicação diária (cerca de 18), mas com a

\footnotetext{
Correspondência / Correspondence:

Lais Gonçalves Parvan

Centro Universitário UNIFAMINAS

Av. Cristiano Ferreira Varella, 65. Bairro Universitário - CEP: 36880-000 - Muriaé, Minas Gerais, Brasil - Tel.: +55 (22) $88122-5366$

E-mail: laisgoncalvesparvan@gmail.com
} 
mortalidade no mesmo patamar ${ }^{5}$. Em 2019, o governo brasileiro liberou mais de 200 tipos de agrotóxicos, dos quais $43 \%$ são altamente tóxicos ${ }^{7}$.

Os pesticidas podem ser agrupados em duas categorias: químicos ou biológicos, de acordo com a Agência de Proteção Ambiental dos Estados Unidos (Environmental Protection Agency). Dentre a categoria dos químicos estão os organofosforados, carbamatos, organoclorados, piretroides e dicarboximidas ${ }^{8}$. Nessa última está o produto deste estudo, que é da classe dos herbicidas seletivos de ação não sistêmica do grupo químico ciclohexenodicarboximida, classificação dicarboximida, cujo mecanismo de ação está pautado na inibição da enzima protoporfirinogênio oxidase. Tais herbicidas necessitam ser ativados pela luz para promover a peroxidação de lipídios, que produzem espécies reativas de oxigênio e causam a morte da célula9. No Brasil, esse composto é classificado toxicologicamente como classe II e classe III quanto ao potencial de periculosidade ambiental e é usado para - controle de ervas daninhas, como a corda de viola (Ipomoea grandifolia) e a erva quente (Spermacoce latifolia), no cultivo da soja, feijão e algodão, e a poaia branca (Richardia brasiliensis), na cultura de milho ${ }^{10,11}$. Segundo a recomendação do fabricante, o herbicida com flumioxazina é perigoso ao meio ambiente e, pela classificação da Agência Internacional de Pesquisa em Câncer (International Agency for Research on Cancer) ${ }^{12}$, está incluído no grupo 3, portanto, não carcinogênico para humanos.

Dessa forma, a preocupação com a exposição a essas classes de agrotóxicos se deve ao fato da maioria desses agentes serem capazes de interagir com o material genético das células, causando lesões que não são possíveis de serem reparadas. Esse acúmulo de danos mutagênicos causa danos genotóxicos que acabam levando à carcinogênese ${ }^{13}$. Porém, vale ressaltar que todos os agentes mutagênicos são genotóxicos e nem todas as substâncias genotóxicas são mutagênicas, justamente porque nem todas são capazes de interagir diretamente com - DNA ${ }^{14}$. Tofolo et al. ${ }^{15}$ alertaram sobre esses riscos à saúde de agricultores submetidos à exposição de pesticidas. Profissionais da indústria agrária são os mais expostos a esses compostos ao manipular, diluir, preparar, aplicar e monitorar as lavouras; porém, não somente esses, mas também aqueles indiretamente expostos, como os indivíduos que moram próximos às lavouras e os familiares que entram em contato com a roupa do profissional que fez o uso de agrotóxicos ${ }^{16}$.

Alguns ensaios de avaliação de genotoxicidade são capazes de detectar aberrações cromossômicas, troca de cromátides irmãs e micronúcleos, enquanto que o ensaio cometa, que é um teste complementar, é utilizado para verificar danos no DNA de forma mais específica $^{17,18}$. O bioensaio com Allium cepa utiliza o aparecimento de anormalidades cromossômicas como um de seus bioindicadores para analisar os efeitos tóxicos, citotóxicos, genotóxicos e mutagênicos de um composto químico em raízes de cebolas. Fiskesjö ${ }^{19}$ ressalta o uso de diferentes sistemas vegetais em ensaios testes para determinações de certos malefícios advindos de compostos químicos. Dentre os vegetais, espécies do gênero Allium são as mais utilizadas para estudos dos mecanismos básicos e de determinação dos efeitos de alguns agentes químicos. Apesar de existirem certas diferenças entre o metabolismo de vegetais e animais, a ativação pró-mutagênica em plantas possui alta relevância, pois seres humanos estão continuamente expostos a esses riscos ao consumir vegetais tratados com agentes químicos ${ }^{20}$. Dentro desse gênero, a Royal Swedish Academy of Sciences tem a espécie $A$. cepa como organismo modelo ${ }^{21}$, além de ser considerado padrão ouro na avaliação de efeitos clastogênicos e aneugênicos sobre o material genético ${ }^{22}$.

composto escolhido como controle positivo, neste estudo, foi o benzoato de sódio 1\%23,24,25. Um estudo avaliou o potencial citotóxico do glutamato monossódico e do benzoato de sódio 1\% por A. cepa e observou toxicidade celular ao reduzir ou, até mesmo, inibir o crescimento das raízes e causar danos celulares. $\bigcirc$ mesmo estudo mostrou que o estresse nas raízes foi maior no tratamento com o benzoato de sódio $1 \%$, evidenciado pela diferenciação celular precoce ${ }^{26}$. Esse composto foi utilizado como controle positivo para efeito de citotoxicidade e auxiliou na validação da técnica em relação à exposição dos bulbos a outra substância que não a testada.

Os ensaios utilizando $A$. cepa têm baixo custo e podem ser realizados em um curto período de tempo, auxiliando nos estudos de prevenção e controle de danos ao meio ambiente ${ }^{19}$. Além disso, destacam-se, ainda, por possuírem elevada sensibilidade e boa correlação com outros sistemas-testes, sendo possível realizar diversas exposições a um mesmo composto para fins de monitoramento. São testes fáceis que apresentam um crescimento rápido de suas raízes, além da facilidade na análise por gerar um grande número de células em divisão ${ }^{22,26}$.

Pela relevância em se investigar possíveis efeitos do uso de agrotóxicos e os riscos à saúde humana, o objetivo deste estudo foi investigar o potencial genotóxico de um herbicida com flumioxazina pelo bioensaio $A$. cepa em duas concentrações diferentes.

\section{MATERIAIS E MÉTODOS}

$\bigcirc$ presente estudo foi desenvolvido seguindo protocolos adaptados de Krüger ${ }^{23}$, e Aiub e Felzenswalb ${ }^{24}$.

\section{PREPARO DA AMOSTRA}

Foram utilizadas 30 cebolas, adquiridas comercialmente, de mesma procedência e tamanho, saudáveis e não enraizadas. Foi feita a raspagem superficial dos bulbos, os quais foram colocados em contato com água destilada, para crescimento das raízes, em copos descartáveis, suspensos por palitos de dente. Essa exposição foi feita no período da manhã, quando ocorre maior número de divisões mitóticas ${ }^{24}$. Foram assim mantidas durante $48 \mathrm{~h}^{23,24,25}$, com trocas dos copos e da água a cada 24 h para que não houvesse a proliferação de fungos. Os horários de troca 
foram definidos a partir da primeira exposição. Todos os 30 bulbos expostos à água destilada apresentaram crescimento das raízes após o período de exposição de $48 \mathrm{~h}$.

Após esse período, os bulbos foram aleatoriamente distribuídos em quatro grupos: controle negativo $(\mathrm{CN})$, com água destilada; controle positivo (CP), com benzoato de sódio $1 \%$; teste 1 , com a substância teste (flumioxazina) à concentração $0,5 \mathrm{~g} / \mathrm{L}$ (concentração indicada para o uso); e teste 2, com flumioxazina a $1,0 \mathrm{~g} / \mathrm{L}$. A amostra foi então exposta por mais 48 h. Os grupos controle foram determinados de acordo com a proporção de $10 \%$ para o número total de cebolas testadas $(N=30)$, representando aproximadamente $30 \%$ do grupo teste $(N=10)$, isso é, $3 \mathrm{CP}$ e $3 \mathrm{CN}$; para os grupos teste, $40 \%$ do total de bulbos, 12 em cada.

\section{PREPARO PARA A ANÁLISE MACROSCÓPICA DE TOXICIDADE}

Ao término do período de exposição de $48 \mathrm{~h}$, foi feita a análise macroscópica das raízes. $\bigcirc$ número total de raízes de todos os 30 bulbos foi contabilizado, e o comprimento das três maiores raízes de cada bulbo foi medido com o auxílio de uma régua. Os resultados obtidos, em relação aos tamanhos das raízes (em centímetros) nas substâncias testes, foram comparados aos grupos controle (positivo e negativo) para determinação da toxicidade.

\section{PREPARO PARA A ANÁLISE MICROSCÓPICA DE CITOTOXICIDADE E GENOTOXICIDADE}

$\mathrm{Na}$ análise citotóxica, as raízes medidas na análise macroscópica foram colocadas sobre a lâmina de acordo com a indicação (por meio de uma seta) da direção da coifa, por ser essa a parte da raiz com maior número de células novas e em divisão celular. As raízes foram então submetidas à coloração com orceína-acética $2 \%$ e aquecidas no bico de Bunsen para fixação e ruptura da parede celular. Foi feita a lavagem das raízes com água destilada para a remoção do excesso de corante e, em seguida, o esmagamento manual com lamínula. Foram contadas 1.000 células em cada uma das raízes. $O$ índice mitótico (IM) foi obtido por meio do total de células em divisão (prófases, pré-metáfases, metáfases, pré-anáfases, anáfases e telófases) em cada 1.000 células analisadas, conforme fórmula a seguir 23 :

$$
I M=\frac{\text { Número de células em divisão }}{1.000}
$$

Para a contagem de aberrações cromossômicas $(A C)$, visando à análise da genotoxicidade, foram quantificadas as seguintes anormalidades: micronúcleos, pontes anafásicas, cromossomos retardatários, quebra cromossômica, anormalidades do fuso e alterações nucleolares. $O$ número total de $A C$ encontradas em 1.000 células foi dividido por 1.000 e multiplicado por 100.

A presença de micronúcleos foi o parâmetro utilizado para analisar o efeito mutagênico. A quantificação foi feita por meio do número de micronúcleos contados em 1.000 células por raiz. No presente estudo, essa presença foi associada ao parâmetro de mutagenicidade, conforme Leme e Marin-Morales ${ }^{25}$ e Carvalho et al. ${ }^{27}$.

\section{ANÁLISE ESTATÍSTICA}

A análise estatística foi realizada por meio do programa SPSS v17.0. Foi realizado o teste de normalidade Kolmogorov-Smirnov. As correlações dos fatores interferentes no crescimento das raízes foram realizadas pelo teste de correlação de Spearman's Rho. As análises de comparação entre os grupos foram obtidas por meio dos testes não paramétricos para amostras independentes (Kruskal-Wallis, para mais de duas amostras, e Mann-Whitney para duas amostras), considerando significante quando $p<0,05$.

\section{RESULTADOS}

\section{ANÁLISE MACROSCÓPICA DAS RAÍZES}

A análise macroscópica foi realizada de forma descritiva em relação ao número, tamanho (Tabela 1) e aspecto das raízes.

Com relação ao aspecto, os bulbos tratados com - CP apresentaram inibição no crescimento das raízes (Figura 1A). No tratamento com flumioxazina $0,5 \mathrm{~g} / \mathrm{L}$ (Figura 1B), não houve inibição do crescimento. Raízes endurecidas, escuras e contorcidas, bem como a presença de necrose nas pontas, foram observadas em ambas as concentrações do herbicida (Figuras 1B e 1C).

Tabela 1 - Média e desvio padrão dos grupos controle e teste, de acordo com o número de raízes de cada bulbo de A. cepa e o tamanho, em $\mathrm{cm}$, das três maiores

\begin{tabular}{lcc}
\hline \multicolumn{1}{c}{ Grupos } & Número de raízes & Tamanho $(\mathrm{cm})$ \\
\hline Controle negativo & $25 \pm 3,46$ (mín. $=21$; máx. $=27)$ & $1,05 \pm 0,08$ \\
Controle positivo & $18 \pm 5,30($ mín. $=14$; máx. $=24)$ & $0,32 \pm 0,01$ \\
Flumioxazina $0,5 \mathrm{~g} / \mathrm{L}$ & $27 \pm 12,10$ (mín. $=9$; máx. $=44)$ & $1,23 \pm 0,02$ \\
Flumioxazina $1,0 \mathrm{~g} / \mathrm{L}$ & $31 \pm 13,60$ (mín. $=14$; máx. $=68)$ & $1,00 \pm 0,03$ \\
\hline
\end{tabular}

mín.: Mínimo; máx.: Máximo. 

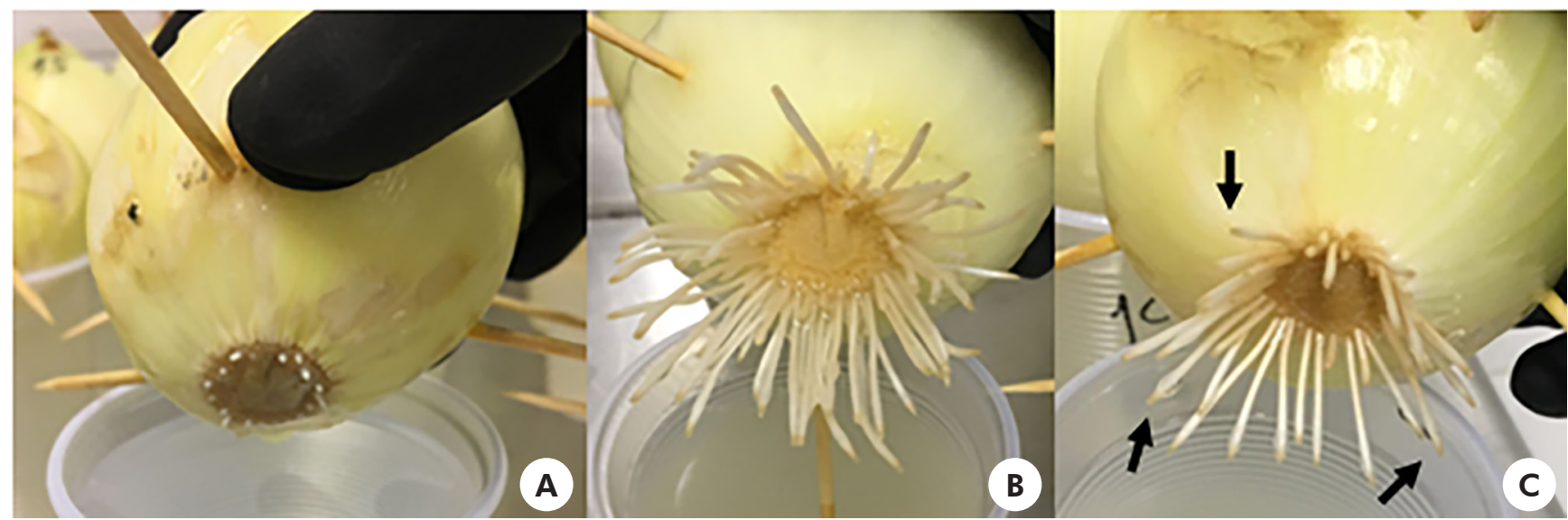

Fotos: Lais Gonçalves Parvan.

A: Inibição do crescimento da raiz tratada com benzoato de sódio 1\% (CP); B: Raízes tratadas com flumioxazina 0,5 g/L; C: Anormalidades, como necrose (setas) e escurecimento da raiz, observadas em ambas as concentrações do herbicida.

Figura 1 - Bulbos de A. cepa após a completa exposição à flumioxazina

\section{ANÁLISE MICROSCÓPICA DAS RAÍZES}

O efeito citotóxico das cebolas foi analisado pelo cálculo do IM (Tabela 2), o efeito genotóxico por contagem de $\mathrm{AC}$ e o efeito mutagênico por contagem de micronúcleos. A citotoxicidade foi calculada observando células em todas as fases do ciclo: prófases, pré-metáfases, metáfases, pré-anáfases, anáfases e telófases ${ }^{24}$.

A frequência de $A C$ foi apresentada na tabela 3. Não foram observadas AC no grupo $C N$. A análise microscópica das raízes nas concentrações teste mostrou AC como pontes anafásicas (Figuras 2A-B), anormalidades do fuso (Figura 2C), metáfase com quebra cromossômica (Figura 2D), cromossomos vagantes (Figuras 2E-F), metáfase anormal (Figura $2 \mathrm{G})$, micronúcleos (Figura 2H) e células necróticas (Figura 2l).

Os grupos $\mathrm{CN}$ e $\mathrm{CP}$ não apresentaram micronúcleos em 1.000 células contadas. As cebolas testadas em flumioxazina $(0,5 \mathrm{~g} / \mathrm{L})$ apresentaram média de $0,1 \pm 0,13$ (mín. $=0 ; \quad$ máx. $=0,4$ ), enquanto as testadas em concentração $1,0 \mathrm{~g} / \mathrm{L}$ apresentaram média de 0,3 $\pm 0,7$ (mín. $=0$; máx. $=0,2$ ).

Tabela 2 - Resultado dos valores do IM de cada grupo

\section{Grupos}

Controle negativo

Controle positivo

Flumioxazina $0,5 \mathrm{~g} / \mathrm{L}$

Flumioxazina $1,0 \mathrm{~g} / \mathrm{L}$
IM (média \pm desvio padrão)

0,0003 \pm 0,0005 (mín. = 0; máx. = 0,0001)

0,0036 \pm 0,005 (mín. =0,00008; máx. =0,007)

0,0033 $\pm 0,0037$ (mín. = 0,00016; máx. =0,012)

$0,0020 \pm 0,0041($ mín. $=0 ;$ máx. $=0,01)$

mín.: Mínimo; máx.: Máximo.

Tabela 3 - Frequência de AC entre os grupos

Grupos

AC (média \pm desvio padrão)

Controle negativo

Controle positivo

0,0002 $\pm 0,00021$ (mín. = 0,00005; máx. =0,00035)

Flumioxazina $0,5 \mathrm{~g} / \mathrm{L}$

0,01 0 0,01 (mín. =0; máx. =0,0002)

Flumioxazina $1,0 \mathrm{~g} / \mathrm{L}$

0,00004 \pm 0,00005 (mín. = 0; máx. = 0,00016)

mín.: Mínimo; máx.: Máximo; Sinal convencional utilizado: - Dado numérico igual a zero, não resultante de arredondamento. 

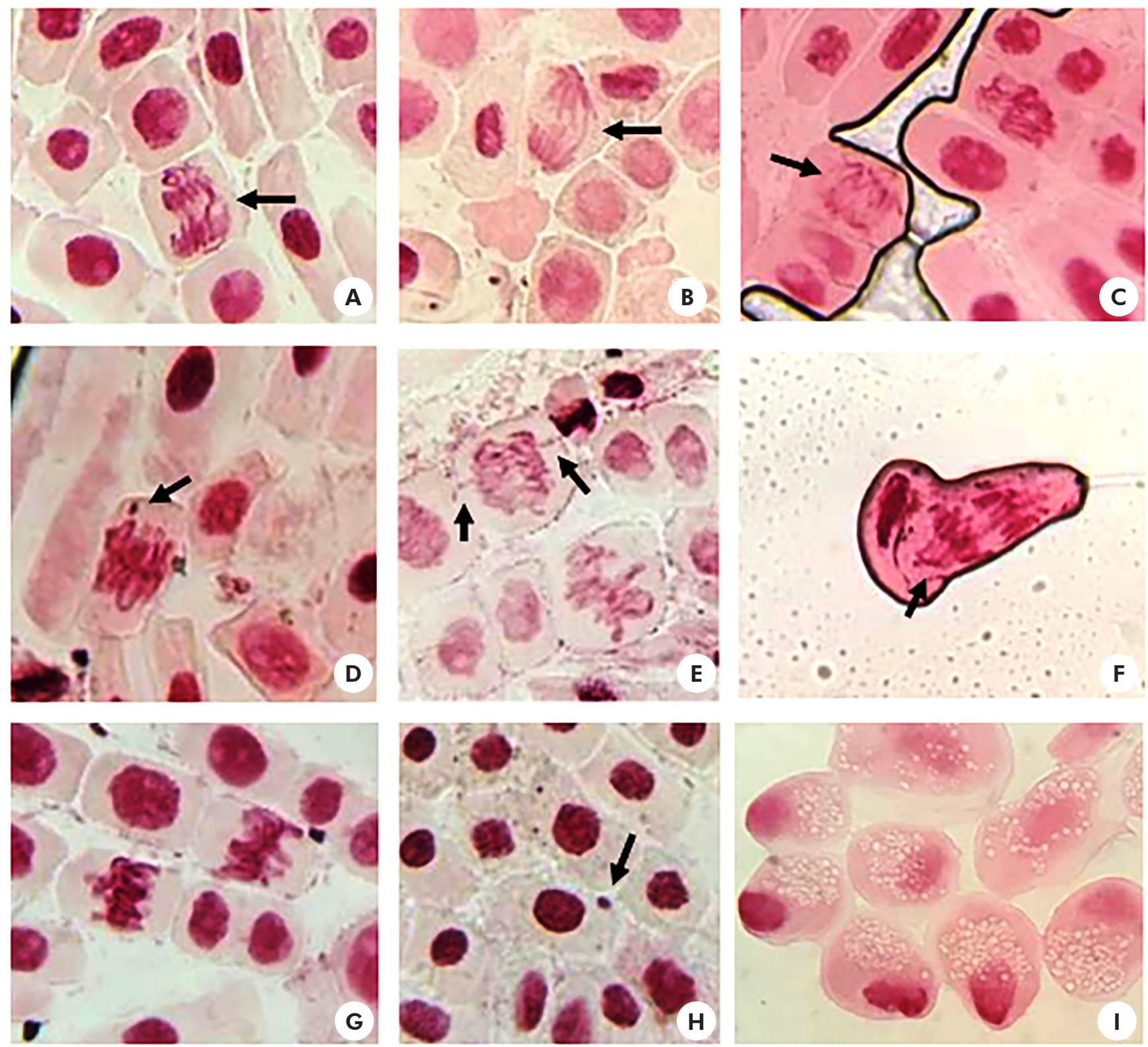

Fotos: Lais Gonçalves Parvan.

Aumento de 40x. A-B: ponte anafásica (seta); C: anormalidades do fuso (seta); D: metáfase com quebra cromossômica (seta); E-F: cromossomo vagante (seta); G: metáfase anormal; H: micronúcleo (seta); I: células necróticas.

Figura 2 - Células meristemáticas de A. cepa tratadas com flumioxazina nas concentrações 0,5 e 1,0 g/L

\section{ANÁLISE ENTRE OS GRUPOS}

Macroscopicamente, o número e o tamanho das raízes de cada grupo foram comparados. Houve associação entre as substâncias testadas e o tamanho das raízes quando analisadas entre todos os grupos $(p=0,03)$. Porém, não houve associação entre 0 número de raízes e as substâncias testadas $(p=0,06)$ (Tabela 4).

Microscopicamente, O IM foi comparado entre os grupos (Tabela 4). Foi demonstrado o efeito citotóxico do herbicida com flumioxazina na concentração 0,5 g/L pela diferença significativa encontrada, quando comparado ao $\mathrm{CN}$.

Entre os grupos, houve diferença estatisticamente significante em relação à presença de $A C$, quando comparado ao $\mathrm{CN}(p=0,04)$. As $A C$ encontradas no herbicida com flumioxazina $0,5 \mathrm{~g} / \mathrm{L}$ apresentaram essa diferença, quando comparadas ao $\mathrm{CN}(\mathrm{p}=0,002)$, assim como na concentração $1,0 \mathrm{~g} / \mathrm{L}(p=0,013)$. Esses resultados sugerem genotoxicidade do herbicida por intervirem no número de $A C$ observadas, quando comparados ao grupo CN (Tabela 4).

Com relação à mutagenicidade, apesar de ter sido observada a presença de micronúcleos em ambas as concentrações testadas, não foi possível observar efeito mutagênico, visto que os resultados estatísticos não foram significantes $(p>0,05)$. Na comparação da quantidade de micronúcleos encontrada nos grupos $\mathrm{CP}$ e $\mathrm{CN}$ com os grupos teste, também não foi verificada diferença estatisticamente significante $(p>0,05)$ (Tabela 4). 
Tabela 4 - Análise geral entre os grupos testados

Análise macroscópica

Análise microscópica

\begin{tabular}{|c|c|c|c|c|c|}
\hline Grupos & $N^{\circ}$ de raízes & $\begin{array}{l}\text { Tamanho } \\
(\mathrm{cm})\end{array}$ & $\begin{array}{c}\text { IM } \\
\text { (análise de efeito } \\
\text { citotóxico) }\end{array}$ & $\begin{array}{c}\text { AC } \\
\text { (análise de efeito } \\
\text { genotóxico) }\end{array}$ & $\begin{array}{l}\text { Micronúcleos } \\
\text { (análise de efeito } \\
\text { mutagênico) }\end{array}$ \\
\hline Controle negativo & 25 & 1,05 & 0,0003 & - & - \\
\hline Controle positivo & 18 & 0,32 & 0,0036 & 0,0002 & - \\
\hline Flumioxazina $0,5 \mathrm{~g} / \mathrm{L}$ & 27 & 1,23 & 0,0033 & 0,01 & 0,1 \\
\hline Flumioxazina $1,0 \mathrm{~g} / \mathrm{L}$ & 31 & 1,00 & 0,0020 & 0,00004 & 0,3 \\
\hline $\begin{array}{l}\text { Estatisticamente } \\
\text { significante? }\end{array}$ & $\begin{array}{c}\text { Não } \\
(p=0,06)\end{array}$ & $\begin{array}{c}\text { Sim, entre todos os } \\
\text { grupos } \\
(p=0,03)\end{array}$ & $\begin{array}{c}\text { Sim } \\
C N \times \text { Flumioxazina } \\
0,5 \mathrm{~g} / \mathrm{L}(\mathrm{p}=0,018)\end{array}$ & $\begin{array}{c}\text { Sim } \\
C N \times \text { Flumioxazina } \\
0,5 \mathrm{~g} / \mathrm{L}(\mathrm{p}=0,002) \\
\text { e CN x Flumioxazina } \\
1,0 \mathrm{~g} / \mathrm{L}(\mathrm{p}=0,013)\end{array}$ & $\begin{array}{c}\text { Não } \\
(p>0,05)\end{array}$ \\
\hline
\end{tabular}

Sinal convencional utilizado: - Dado numérico igual a zero, não resultante de arredondamento.

\section{DISCUSSÃO}

herbicida com flumioxazina foi escolhido por ser utilizado por agricultores na região da Zona da Mata, no estado de Minas Gerais, principalmente em culturas de soja e feijão ${ }^{12}$. $O$ estudo mostrou que o herbicida, em ambas as concentrações testadas, foi tóxico às raízes ao provocar alterações nas células vegetais aqui analisadas, como necroses nas pontas.

$\mathrm{Na}$ análise microscópica, foi possível constatar que o herbicida com flumioxazina, na concentração recomendada para o uso $(0,5 \mathrm{~g} / \mathrm{L})$, apresentou sinais de citotoxicidade. Além disso, foram verificados efeitos de genotoxicidade em ambas as concentrações testadas, por provocar AC nas células da cebola.

Embora tenham sido observados micronúcleos nas concentrações testadas, não foi encontrada significância estatística quando comparadas aos grupos CN e CP. Os micronúcleos podem ser originados de forma espontânea, portanto, novos estudos devem ser realizados para verificar a formação dos mesmos.

$\bigcirc$ fato desse herbicida ter apresentado efeito citotóxico e genotóxico mostra a importância do monitoramento dessas substâncias químicas e seus efeitos nos organismos vivos, visto que as alterações provocadas a nível molecular afetaram diretamente o material genético na amostra analisada.

$\bigcirc$ teste $A$. cepa iá foi utilizado em várias análises, como na avaliação da genotoxicidade de medicamentos $^{28}$, de infusões de plantas medicinais ${ }^{29}$ e na avaliação da qualidade de águas de $\operatorname{rios}^{30}$. É um teste que, quando necessário, pode ser complementado pelo teste cometa na análise de fragmentação do DNA das células, para que os efeitos encontrados sejam adequadamente associados e ter sua causa investigada. Sugere-se que o teste cometa seja realizado para complementar os testes de genotoxicidade, e que um número maior de bulbos para os controles seja adicionado para aumentar o poder estatístico na comparação entre os grupos.

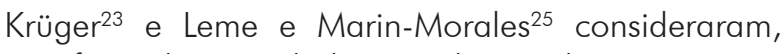
como efeito de toxicidade, a inibição do crescimento radicular. No presente estudo, dois fatores foram analisados para determinar a toxicidade: a alteração do tamanho/número e as $A C$ das raízes. $\bigcirc$ efeito tóxico pode ser mascarado pela presença de macronutrientes inorgânicos (por exemplo, nitrogênio e fósforo), resultando em alongamento das raízes da cebola ${ }^{31}$. Porém, a determinação do efeito tóxico foi baseada na presença de $A C$, como necroses, raízes distorcidas e escurecidas, observadas no tratamento com flumioxazina em ambas as concentrações.

As plantas possuem mecanismos de autodefesa que podem ser enfraquecidos quando são expostas a situações de estresse ambiental. Por isso, o uso excessivo de defensivos, além de nem sempre deter as pragas, pode provocar o surgimento de doenças nas plantas. Assim, o herbicida como agente estressor pode ser prejudicial às raízes, provocando alterações radiculares e morte prematura das mesmas ${ }^{32}$.

A citotoxicidade foi analisada pela determinação do IM, que é utilizado como um biomarcador de proliferação celular ao medir a proporção de células em divisão nas diversas fases do ciclo celular ${ }^{25,33}$. $\bigcirc$ presente estudo identificou citotoxicidade na concentração 0,5 g/L ao apresentar diferenças estatisticamente significantes do IM, quando comparado ao grupo CN. Tanto o aumento quanto a diminuição desse índice indicam citotoxicidade: o aumento sugere desordem celular ao provocar a multiplicação das divisões celulares; e a redução indica dano no DNA, que leva à parada no ciclo celular na tentativa de reparo ${ }^{25}$. Houve associação do IM com o herbicida na concentração 0,5 g/L e o CN quando associado às $A C(p=0,018)$, sugerindo que quanto maior $I M$, maior o número de $A C$.

Vale ressaltar que o aumento do IM pode estar relacionado ao aumento no tamanho das raízes. Dois estudos constataram o mesmo efeito ao analisar a citotoxicidade de águas de rios, observando que, quanto 
maior o IM, maior o tamanho das raízes ${ }^{34,35}$. Do mesmo modo, diversos estudos demonstraram essa relação ao observar que a diminuição desse índice também causa inibição do crescimento radicular23,35,36.

A presença de AC foi associada ao efeito genotóxico. As substâncias genotóxicas nem sempre interagem diretamente com o DNA. Porém, aquelas capazes de causar essa interferência induzem danos ao material genético nas células por meio de interações com a sequência e a estrutura do DNA. Essas anomalias cromossômicas em células de A. cepa são um parâmetro eficiente para a investigação do potencial genotóxico de compostos químicos, pois fornecem informações que devem ser consideradas essenciais no processo de carcinogênese ${ }^{25}$. Agentes genotóxicos são capazes de atuar amplamente sobre a célula, seja na organização de suas organelas ou de seus compartimentos, além de causar alterações que podem afetar o ciclo celular, desregulando suas fases, gerando células aberrantes e, até mesmo, induzi-las à morte ${ }^{37}$.

presente estudo sugeriu efeito genotóxico do herbicida com flumioxazina nas duas concentrações testadas e ainda demonstrou a associação entre o número de $A C$ e IM. É conhecida a capacidade de herbicidas provocarem anomalias celulares. Plantas de sorgo tratadas com o herbicida Atrazina apresentaram maior número de cromossomos, células binucleadas e anormalidades em células-mãe de grãos-de-pólen, o que comprova a interferência do herbicida na estabilidade da meiose ${ }^{38}$.

Efeitos clastogênicos (quebras no DNA) nas espécies Pisum sativum e $A$. cepa, induzidas pelo tratamento com herbicidas, também demonstram efeitos de indução a quebras cromossômicas no DNA ${ }^{39}$. Fernandes ${ }^{2}$ considerou uma ação aneugênica que impede a segregação simétrica do material genético durante a divisão celular, levando a um desequilíbrio genômico. Pelos resultados deste estudo, é possível sugerir ações aneugênicas pela presença de cromossomos vagantes e retardatários, ou seja, que não foram segregados corretamente, bem como ações clastogênicas, principalmente nas amostras tratadas com o benzoato de sódio 1\%, por apresentar essa ação conhecida.

Também foi possível observar a presença de necrose, em nível microscópico, na concentração de 1,0 g/L (Figura 2l), que pode ser explicada pela resposta da célula a danos irreversíveis provocados no material genético ${ }^{40}$. Diferentes mecanismos de manutenção da homeostase celular estão ligados ao processo de divisão celular, ao metabolismo celular e à morte celular. Falhas nesses mecanismos por falta de reparo podem promover a transformação neoplásica e caracterizar o início do processo de formação de tumores. Dessa forma, células não reparadas são encaminhadas para o processo de morte celular, também chamado de necroptose na patologia, ou necrose celular programada, no intuito de evitar o desencadeamento de tumores ${ }^{41}$. Por isso, é importante estudar fatores e/ou substâncias que podem interferir no ciclo celular, como realizado neste estudo.
$\mathrm{Na}$ investigação da mutagenicidade, a análise foi feita por meio da contagem de micronúcleos. Existem divergências no conceito de mutagenicidade por diferentes autores. Leme e Marin-Morales ${ }^{25}$ e Carvalho et al. ${ }^{27}$ consideram a presença dos micronúcleos como um parâmetro para mutagenicidade, enquanto Krüger $^{23}$ e Fenech ${ }^{42}$ consideram como parâmetro de genotoxicidade. Micronúcleos se originam de fragmentos cromossômicos acêntricos ou são formados em células em divisão que apresentam fragmentos cromossômicos inteiros que interromperam a capacidade de se ligar ao fuso mitótico, ou seja, não completam a migração anafásica da divisão celular ${ }^{42}$. Tal característica indica a presença de substâncias com efeitos mutagênicos.

presente estudo, apesar de apresentar células com a presença de micronúcleos nas raízes tratadas com flumioxazina nas concentrações testadas, não confirmou a mutagenicidade do composto por não apresentar significância estatística quando comparados ao grupo $\mathrm{CN}$ e CP. A indução de micronúcleos é comumente usada na detecção de danos genotóxicos e mutagênicos resultantes da exposição a agentes tóxicos. Porém, os micronúcleos também podem se originar espontaneamente 43 , podendo ser da ordem de 3/1.000 células analisadas ${ }^{42,44}$. Assim, o efeito mutagênico, devido à presença de micronúcleos em uma substância testada, deve ser criteriosamente analisado.

Quanto aos efeitos genotóxicos, uma revisão sistemática de publicações sobre o impacto do uso de agrotóxicos no meio ambiente, produzidas no período de 2011 a 2017, evidenciou o prejuízo causado pelo uso dessas substâncias, muitas vezes, por alterarem 0 habitat natural dos ecossistemas ${ }^{45}$. Esses riscos não são somente para o meio ambiente, mas também para a saúde humana, principalmente de agricultores e manipuladores que são sucessivamente submetidos à exposição de pesticidas. $\bigcirc$ não uso de proteções adequadas e o desrespeito aos limites de concentrações de uso permitidos pelos órgão de fiscalização aumentam os problemas de saúde e os danos ambientais ${ }^{15}$.

- mapa de uso de agrotóxicos nos municípios do sudoeste do Paraná mostrou que a produção de commodities, como soja, milho e trigo, tem sido responsável pelo consumo exorbitante de agrotóxicos nos municípios em questão, de modo que os principais ingredientes ativos utilizados desencadeiam alto risco de contaminação ambiental e também para a saúde humana. $\bigcirc$ herbicida abordado neste estudo é muito utilizado no Brasil no controle de ervas daninhas nessas culturas $^{46}$.

É importante conhecer os efeitos e possíveis riscos relacionados às exposições excessivas aos agrotóxicos utilizados. Os testes de monitoramento dessas substâncias, quer os que indicam o grau de exposição genotóxica dos indivíduos, como o bioensaio com A. cepa, ou aqueles que determinam os efeitos desses compostos in vitro, são fundamentais ao monitorar as implicações futuras à saúde humana. 
As exposições excessivas aos agrotóxicos não estão somente nos alimentos contendo resíduos, mas também no contato dos trabalhadores rurais e familiares que, ao manipularem esses compostos, tornam-se os mais suscetíveis aos danos. Um dos problemas das sucessivas exposições a esses herbicidas está no fato de que eles levam a um acúmulo de mutações que, em um momento superior, poderão provocar alterações mutagênicas e carcinogênicas. $\bigcirc$ desenvolvimento do câncer não representa o único dano de exposição a essas substâncias; as intoxicações agudas e crônicas também podem ocorrer. $\bigcirc$ uso de monitores ambientais para a avaliação das atividades citotóxicas, genotóxicas e mutagênicas de químicos ambientais, principalmente os agrotóxicos, deve ser considerado como potencial indicador de risco para a saúde humana e para o meio ambiente.

\section{CONCLUSÃO}

herbicida com flumioxazina, em ambas as concentrações, apresentou efeitos de toxicidade devido às necroses e anomalias observadas em suas raízes. A citotoxicidade foi detectada na concentração de uso, e a genotoxicidade foi observada nas duas concentrações testadas. Efeitos mutagênicos não foram constatados.

\section{AGRADECIMENTOS}

À UNIFAMINAS, pela execução do trabalho; ao Instituto Federal Sudeste, pela parceria; e ao CNPq, pelo suporte.

\section{APOIO FINANCEIRO}

Conselho Nacional de Desenvolvimento Científico e Tecnológico, CNPq.

\section{CONFLITOS DE INTERESSES}

Não houve conflito de interesses no presente estudo.

\section{CONTRIBUIÇÃO DOS AUTORES}

Todos os autores contribuíram com a idealização do estudo, a análise e a interpretação dos dados e com a redação do manuscrito, aprovando a versão final publicada. Declaram-se responsáveis pelo conteúdo integral do artigo, garantindo sua precisão e integridade.

\section{REFERÊNCIAS}

1 Ventura BC. Avaliação dos efeitos citotóxicos, genotóxicos e mutagênicos do herbicida Atrazina, utilizando Allium cepa e Oreochromis niloticus como sistemas-teste [dissertação]. Rio Claro (SP): Universidade Estadual Paulista, Instituto de Biociências; 2004.

2 Fernandes TCC. Investigação dos efeitos tóxicos, mutagênicos e genotóxicos do herbicida trifluralina, utilizando Allium cepa e Oreochromis niloticus como sistemas-testes [dissertação]. Rio Claro (SP): Universidade Estadual Paulista, Instituto de Biociências; 2005.

3 Oliveira LCC. Resíduos de agrotóxicos nos alimentos, um problema de saúde pública [trabalho de conclusão de curso]. Uberaba (MG): Universidade Federal do Triângulo Mineiro; 2014.

4 Valentim LSO, Veiga DPB, Mário Jr RJ, Elmec AM. Água potável e resíduos de agrotóxicos no estado de São Paulo. BEPA. 2019;16(186):43-53.

5 Fundação Oswaldo Cruz. Centro de Informação Científica e Tecnológica. Sistema Nacional de Informações Tóxico-Farmacológicas. Tabela 2. Casos, óbitos e letalidade de intoxicação humana por região e centro. Brasil, 2017 [Internet]. Rio de Janeiro: Fiocruz; 2017 [citado 2019 jun 13]. Disponível em: https://sinitox.icict.fiocruz.br/sites/ sinitox.icict.fiocruz.br/files//Brasil2_1.pdf.

6 Bombardi LM. Geografia do uso de agrotóxicos no Brasil e conexões com a União Europeia. São Paulo: FFLCH-USP; 2017.
7 Greenpeace. Unearthed. Brazil pesticide approvals soar as Jair Bolsonaro moves to weaken rules [Internet]. 2019 Jun [cited 2019 Dec 1]. Available from: https://unearthed.greenpeace. org/2019/06/12/jair-bolsonaro-brazil-pesticides/.

8 Oga S. Fundamentos da toxicologia. São Paulo: Atheneu; 1996. 515 p.

9 Rodrigues MAT. Classificação de fungicidas de acordo com o mecanismo de ação proposto pelo FRAC [dissertação]. Botucatu (SP): Universidade Estadual Paulista, Faculdade de Ciências Agronômicas; 2006.

10 Flumyzin 500 [Internet]. Curitiba (PR): Agência de Defesa Agropecuária do Paraná; 2009 [citado 2019 jan 23]. Disponível em: http://www.adapar. pr.gov.br/arquivos/File/defis/DFI/Bulas/Herbicidas/ FLUMYZIN 500.pdf.

11 Pedrosa PAA. Análise macroscópica e microscópica da toxicidade do herbicida Flumyzin 500 (Flumioxazina) pelo bioensaio Allium cepa [dissertação]. Muriaé (MG): Centro Universitário Unifaminas; 2017.

12 World Health Organization. International Agency for Research on Cancer. Occupational exposures in insecticide application, and some pesticides. Lyon (FR): IARC; 1987. (IARC monographs on the evaluation of carcinogenic risks to humans; vol. 53).

13 Griffiths AJF, Miller JH, Suzuki DT, Lewontin RC, Gelbart WM, Wessler SR. Introdução à genética. 9. ed. Rio de Janeiro: Guanabara Koogan, 2009. 
14 Ribeiro LR, Salvadori DF, Marques EK, organizadores. Mutagênese ambiental. Canoas: ULBRA; 2003.

15 Tofolo C, Fuentefria AM, Farias FM, Machado MM, Oliveira LFS. Contributing factors for farm workers' exposure to pesticides in the west of the state of Santa Catarina, Brazil. Acta Sci Health Sci. $2014 ; 36(2): 153-9$.

16 Peres F, Rozemberg B, Alves SR, Moreira JC, Oliveira-Silva JJ. Comunicação relacionada ao uso de agrotóxicos em uma região agrícola do estado do Rio de Janeiro. Rev Saude Publica. 2001 dez;35(6):564-70.

17 Valente D, Costa-Amaral IC, Carvalho LVB, Santos MVC, Castro VS, Rodrigues DRF, et al. Utilização de biomarcadores de genotoxicidade e expressão gênica na avaliação de trabalhadores de postos de combustíveis expostos a vapores de gasolina. Rev Bras Saude Ocup. 2017 abr;42(supl 1):e2s.

18 Collins AR, Azqueta A. DNA repair as a biomarker in human biomonitoring studies; further applications of the comet assay. Mutat Res. 2012 Aug;736(1-2): 122-9.

19 Fiskesjö G. The Allium test as a standard in environmental monitoring. Hereditas. 1985 Mar; 102(1):99-112.

20 Grippa GA, Morozesk M, Nati N, Matsumoto ST. Estudo genotóxico do surfactante Tween 80 em Allium cepa. Rev Bras Toxicol. 2010;23(1-2):1 1-6.

21 Cabrera GL, Rodriguez DM. Genotoxicity of soil from farmland irrigated with wastewater using three plant bioassays. Mutat Res. 1999 May;426(2):21 1-4.

22 Bagatini MD, Silva ACF, Tedesco SB. Uso do sistema teste de Allium cepa como bioindicador de genotoxicidade de infusões de plantas medicinais. Rev Bras Farmacogn. 2007 jul-set; 17(3):444-7.

23 Krüger RA. Análise da toxicidade e da genotoxicidade de agrotóxicos utilizados na agricultura utilizando bioensaios com Allium cepa [dissertação]. Nova Hamburgo (RS): Centro Universitário Feevale; 2009.

24 Aiub CAF, Felzenswalb I. O uso de Allium cepa como modelo experimental para investigar gentoxicidade de substâncias usadas em conservantes alimentares. Rev Genet Esc. $2011 ; 6(1): 12-15$.

25 Leme DM, Marin-Morales MA. Allium cepa test in environmental monitoring: a review on its application. Mutat Res. 2009 Jul-Aug;682(1):71-81.

26 Pessoa LGA, Bohm PAF, Bohm FMLZ. Avaliação do potencial citotóxico do glutamato monossódico e benzoato de sódio. In: $1^{\circ}$ Encontro Anual de Iniciação Científica, $5^{\circ}$ Seminário de Pesquisa e Pós-graduação; 2015 out 27-29; Campo Mourão, PR.
27 Carvalho LG, Britto FF, Marin-Morales MA, Maffei EMD. Análises citológicas do inseticida Deltametrina usando o Teste de Micronúcleo. Rev Biol. $2017 ; 17(1): 1-5$.

28 Jesus AM, Zamberlam CR. Genotoxicidade do diazepam e potencial de reversão do Ginkgo biloba pelo método Allium cepa. Rev Saude. 2018;12(1 esp):10.

29 Silva JDA, Nogueira CR, Vieira MC, Heredia-Vieira SC, Barufatti A, Crispim BA, et al. Propriedades toxicológicas de um extrato aquoso de folhas de Aristolochia triangularis utilizando os bioensaios de letalidade com Artemia salina e Allium cepa. Cienc Rural. 2019;49(8):e20190091.

30 Rodrigues GZP, Dalzochio T, Gehlen G. Uso do bioensaio com Allium cepa L. e análises físico-químicas e microbiológicas para avaliação da qualidade do Rio da Ilha, RS, Brasil. Acta Toxicol Argent. 2016;24(2):97-104.

31 Rodrigues SC, Bianchini A. Extraction and concentration of freshwater - and seawater - derived dissolved organic matter for use in aquatic toxicology studies. J Braz Soc Ecotoxicol. $2007 ; 2(3): 275-81$.

32 Tsuzuki Y. Defesa fisiológica contra doenças e pragas. São Paulo: Gráfica Paulo's; 2010. 97 p.

33 Mercado SAS, Caleño JDQ. Cytotoxic evaluation of glyphosate, using Allium cepa L. as bioindicator. Sci Total Environ. 2020 Jan;700: 134452.

34 Motta LS, Damasceno JM, Pereira IFM, Vidal ACB, Silva DC, Silva PT, et al. Bioensaio com Allium cepa L. revela ação tóxica e citogenotóxica na água do Rio São Francisco sob influência do canal do Tourão (Juazeiro/BA). Semina Cien Biolog Saude. 2017 mai-jun;38(supl 1): 109.

35 Braga JRM, Lopes DM. Citotoxicidade e genotoxicidade da água do rio Subaé (Humildes, Bahia, Brasil) usando Allium cepa L. como bioindicador. Rev Ambient Agua. 2015 jan-mar; 10(1): 130-40.

36 Tedesco SB, Laughinghouse IV HD. Bioindicator of genotoxicity: the Allium cepa test. In: Srivastava JK, editor. Environmental contamination. Rijeka (HR): InTech; 2012. Chapter 8; p. 137-56.

37 Kaioumova D, Süsal C, Opelz G. Induction of apoptosis in human lymphocytes by the herbicide 2,4-dichlorophenoxyacetic acid. Hum Immunol. 2001 Jan;62(1):64-74.

38 Liang GHL, Feltner KC, Liang YTS, Morrill JL. Cytogenetic effects and responses of agronomic characters in grain sorghum (Sorghum vulgare Pers.) following atrazine application. Crop Sci. 1967 May;7(3):245-8. 
39 Grant WF, Owens ET. Chromosome aberration assays in Pisum for the study of environmental mutagens. Mutat Res. 2001 May;488(2):93-118.

40 Elmore S. Apoptosis: a review of programmed cell death. Toxicol Pathol. 2007 Jun;35(4):495-516.

41 Amabis JM, Martho GR. Biologia das células. 4. ed. Vol. 1. São Paulo: Moderna; 2015.

42 Fenech $M$. The in vitro micronucleus technique. Mutat Res. Nov;455(1-2):81-95.

43 Heddle JA, Carrano AV. The DNA content of micronuclei induced in mouse bone marrow by $\gamma$-irradiation: evidence that micronuclei arise from acentric chromosomal fragments. Mutat Res. 1977 Jul;44(1):63-9.
44 Rabello-Gay MM, Rodrigues MALR, Monteleone-Neto R. Mutagênese, carcinogênese e teratogênese: métodos e critérios de avaliação. Ribeirão Preto: Sociedade Brasileira de Genética; 1991. 246 p.

45 Lopes CVA, Albuquerque GSC. Agrotóxicos e seus impactos na saúde humana e ambiental: uma revisão sistemática. Saúde Debate. 2018 abr-jun;42(1 17 ):518-34.

46 Gaboardi SC, Candiotto LZP, Ramos LM. Perfil do uso de agrotóxicos no Sudoeste do Paraná (2011-2016). Rev Nera. 2019;46(22):13-40.

Recebido em / Received: 29/12/2019 Aceito em / Accepted: 30/6/2020 